\title{
Mekanisme Simpan Pinjam Di Koperasi Sinar Mas dalam perspektif Hukum \\ Islam( Studi Kasus Koperasi Simpan Pinjam Mas sinar Kelurahan, calaca )
}

Oleh: Yusnita Dasim

\begin{abstract}
ABSTRAK
Yang di maksud dengan mekanisme simpan pinjam dalam sperpektif hukum islam adalah bagaimana pandangan hukum islam tentang mekanisme simpan pinjam yang ada di koperasi Mas Sinar Kelurahan. Calaca.

Di mana praktek simpan pinjam yang di terapkan sebagaimana layaknya koperasi pada umumnya tetapi juga memakai sistem pegadaian dengan cara memberikan pinjaman dengan jaminan barang berupa emas.

Kenyataan yang di temukan penulis adalah bahwa mekanisme simpan pinjam yang di terapkan oleh koperasi Mas sinar keberadaannya bagi masyarakat baik kebutuhan hidup sehari- hari ( Konsumtif) maupun sebagai modal usaha (Produktif). Disisi lain mekanisme yang di terapkan sedikit menyulitkan karena cairnya pinjaman tergantung pada ada tidaknya jaminan barang berupa mas dari peminjam juga secara hukum Islam mengalami penyimpangan hokum. Hal ini dapat dibuktikan dengan penerapan bunga yang melebihi $20 \%$.
\end{abstract}




\section{PENDAHULUAN}

\section{A. Latar Belakang Masalah}

Sistem ekonomi, merupakan suatu rahmat yang tidak ternilai bagi umat manusia. Seandainya sistem tersebut dilaksanakan secara menyeluruh dan sesuai dengan agamanya, akan menjadi sarana yang dapat memberikan kepuasan bagi setiap kebutuhan masyarakat.Melakukan kegiatan ekonomi adalah merupakan tabiat manusia untuk memenuhi kebutuhan hidupnya. Dengan kegiatan itu ia memperoleh rizeki dan dengan rezeki itu ia kemudian dapat melangsungkan hidupnya. Bagi orang islam , Alqur'an adalah petunjuk memenuhi kebutuhan hidupnya yang berkeberatan absolute. Sunnah rasulullah saw berfungsi menjelaskan kandungan alqur'an. ${ }^{1}$

Dalam islam, Allah swt tidak hanya mengatur kegiatan hubungan antara manusia dengan tuhan tetapi juga mengatur hubungan antara manusia dengan manusia bahkan mengatur hubungan manusia dengan lingkungannya, yang kita kenal dengan mua'amalah. ${ }^{2}$

Muamalah mencakup kegiatan jual beli , hutang piutang, gadai , pinjam meminjam, senya menyewa, syirkah dan beberapa masalah lainnya yang berkaitan dengan ekonomi. Oleh karena itu di perlukan aturan tertentu agar persaingan tetap berjalan pada batas yang sewajar dan tidak ada pihak yang Baling merugikan. ${ }^{3}$

Sebagaimana yang sudah di gariskan dalam UUD 1945 pasal 33 ayat 1 bahwa perekonomian di susun sebagai sebagai suatu usaha bersama dan berdasarkan asas kekeluargaan. Dari pasal tersebut di tegaskan bahwa badan usaha yang sesuai dengan hal ini adalah koperasi. ${ }^{4}$

1 Muhammad Ajaj Al - Khatib , Ushul al-Hadist Mustalahub (Cet, I;- Beirut : Darul Fikr,1989), h.46

${ }^{2}$ H.A. Nawawi Rambe, Fiqh islam (Cet, I;Jakarta : Duta pahala ,1994),h.441 .

${ }^{3}$ Ibid,h.19

${ }^{4}$ M,Solly Lubis , Pembahasan UUD 1945 (Cet,I;Jakarta :CV ,Rajawali ,1987),h.279. 
Dalam Undang-Undang No.12 tahun 1967 Bab III bagian 1 pasal 3 memberikan pengertian koperasi sebagai koperasi Indonesia.

Adalah kumpulan dari orang -orang yang sebagai manusia secara bersamasama bergotong royong berdasarkan persamaan, bekerja untuk memajukan kepentingan - kepentingan ekon omi dan kepentingan masyarakat. ${ }^{5}$

Namun mekanisme simpan pinjam di koperasi Mas Sinar Kelurahan Calaca merupakan suatu mekanisme simpan pinjam yang baru di mana cairnya dana pinjaman harus mempergunakan jaminan emas. Besar pinjaman haruslah sesuai dengan berat jaminan yang di berikan dan jangka waktu pinjaman selama 1 bulan dengan bunga 5\%. Jadi selama 3 bulan bunganya menjadi $15 \%$.

Berdasarkan hal itu, maka penulis tertarik mencari jawaban atas permasalahan di atas, demi kejelasan mekanisme simpan pinjam dewasa ini, khusunya pada koperasi Mas Sinar Kelurahan Calaca.

\section{B. Rumusan dan Batas Masalah}

Koperasi merupakan suatu wadah yang di anggap masyarakat dapat membantu dan mengurangi baban hidup mereka. Tetapi bagaimana mekanisme simpan pinjam di Koperasi Mas Sinar Kelurahan Calaca? Atas dasar inilah dirumuskan permasalahan sebagai berikut:

1. Bagaimana mekanisme simpan pinjam di Koperasi Mas Sinar Kelurahan Calaca?

2. Bagaimana perspektif hokum islam terhadap mekanisme simpan pinjam di koperasi Mas Sinar Kelurahan Calaca?

\footnotetext{
${ }^{5}$ Ibid,h.222
} 


\section{Hipotesis}

Hipotesis yang digunakan berdasarkan latar belakang, rumusan dan batasan masalah diatas, adalah ;

Mekanisme simpan pinjam di koperasi Mas Sinar Kelurahan Calaca berbeda dengan sistem yang ada di koperasi lain, bahkan di pandang menyulitkan masyarakat utamanya dalam mendapatkan pinjaman, karena yang menjadi jaminan atas pinjaman adalah emas dan bukan uang,simpanan dan tidak semua orang memiliki emas.

Islam melarang umatnya antara satu dan lainnya saling mendzalimi, apalagi memberikan beban berat terhadap umat yang ekonominya lemah dengan ketetapan pengembalian yang berlebihan.

\section{D. pengertian judul}

Judul skripsi ini adalah mekanisme simpan pinjam di koperasi Mas Sinar dalam Perspektif Hukum Islam (Studi Kasus Koperasi Mas Sinar Kelurahan Calaca). Maka untuk menghindari kesalahan interprestasi ( pemahaman) dari para pembaca, penulis akan memberikan pengertian atas kata-kata penulis cantumkan dalam judul di maksud, sebagai berikut ;

Mekanisme berarti tata cara atau kebiasaan. ${ }^{6}$

Simpan berarti meletakkan sesuatu islam berarti bagaimana kah panfdangan hokum islam tentang di tempat yang baik dan aman. ${ }^{7}$

Pinjam berarti memakai barang (uang ) orang lainuntuk sementara waktu. ${ }^{8}$ Jaminan adalah tanggungan atas sesuatu pinjaman yang diterima. ${ }^{9}$

6 M.D.J.Al -Barry- sofyan Hadi A.T, Kamus Ulama Kontenporer(Cet .I; Bandung CV.Pustaka setia,2000),h.205

Peter salim dan Yeni salim,Kamus Bahasa Indonesia Kontenporer (Cet.I;Jakarta modern English Press, 1991),h.1427.

${ }^{8}$ Ibid,h.1023. 
Emas berarti logam,mulia yang biasa di buat perhiasan. ${ }^{10}$

\section{E. Metode penelitian}

Untuk sampai pada tujuan yang di maksud, maka tentu ada suatu cara atau sistem yang sistematik. Oleh sebab itu dalam penulisan skripsi ini penulis menggunakan metode-metode sebagai berikut;

1. Metode pengumpulan data

Metode pengumpulan data, penulis menggunakan cara atau metode sebagai berikut;

2. Metode Library research (penelitian Kepustakaan)

3. Metode Field research (Penelitian Lapangan).

4. Metode pengolahan dan Analisis Data

\section{F. Tujuan dan KegunaanPenelitian}

a. tujuan penelitian

salah satu dari alternative berikut;

a. Menemukan atau merumuskan teori

b. Mengembangkan suatu teori

c. Menguji kebenaran suatu teori

\section{KERANGKA TEORITIS SIMPAN PINJAM}

\section{A. Pengertian simpan pinjam}

Menurut bahasa, simpan (menyimpan) berarti meletakkan sesuatu di tempat yang aman dan baik. Dan pinjam (meminjam) berarti memakai barang, uang orang lain untuk sementara waktu.

\footnotetext{
${ }^{9}$ Ibid,h.1165-1166.

${ }^{10}$ Ibid,h.769.
} 
Sedangkan simpan pinjam dalam koperasi lebih di kenal dengan koperasi kredit yaitu bertujuan untuk menerima tabungan dan memberi pinjaman kepada para anggota dengan syarat-syarat yang mudah dan dengan bunga yang rendah.

Sementara pengertian yang di kehendaki dalam bahasa ini bukanlah sebagaimana yang tersurat dalam pengertian, karena dalam koperasi pun tidak ada aturan baku tentang mekanisme simpan pinjam secara keseluruhan, yang ada hanyalah aturan simpan pinjam meminjam, meskipun dalam sejumlah pinjaman di potong $10 \%$ untuk simpanan pokok dan simpanan wajib bagi setiap peminjam.

Pinjam meminjam dalam islam di kenal dengan istilah Ariyah.

Menurut bahasanya,Ariyyah atau Ariyah di artikan dengan beberapa makna yaitu :

1. Ariyah adalah Hama untuk barang yang di pinjam oleh umat manusia secara bergiliran antara mereka. Perkataan itu di ambil dari masdar at-ta'awur dengan memakai artinya perkataan at-tadawul ${ }^{11}$

2. Ariyah adalah hama barang yang di tuju oleh orang yang meminjam. Jadi perkataan itu di ambil dari akar kata 'arahu-ya'ruhu-' ,urwan. ${ }^{12}$

3. Ariyah adalah Hama barang yang pergi dan dating secara cepat. Diambil dari akar kata'ara yang artinya pergi dan datang secara cepat. Itulah makna dan perkataan ariyah yang shahih.

Adapun pinjaman secara terminologi bahwa pinjam meminjam adalah memberikan sesuatu yang halal kepada orang lain untuk di ambil manfaatnya dengan tidak merusak zatnya,agar dapat di kembalikan zat barang itu. ${ }^{13}$

11 Muhammad Zuhri Dipl Tafl ,at,al,fiqh Empat Mazhab (Cet,I;Semarang : CV .AsySyifa',1994),h.448

12 Ibid

${ }^{13}$ Suhadrawardi Lubis, Hukum Ekonomi islam (cet.I; Jakarta : Sinar Grafika, 2000), h. 126 


\section{B. Dasar Hukum Pinjam Meminjam}

Meminjamkan pada hakekatnya merupakan sebagian amal kebaikan yang di kehendaki oleh kemanusiaan. Sebab umat manusia tentu membutuhkan pertolongan dari sebagian mereka terhadap yang lain.

Adapun dasar hukum yang menjadi dasar hukum perjanjian pinjam meminjam ini dapat disandarkan kepada ketentuan Alqur'an dan sunnah Nabi Muhammad saw. Allah berfirman dalam QS. Al-maidah (5) ; 2 yang Artinya :

"Bertolong -tolonglah kamu dalam kebaikan dan taqwa,dan janganlah bertolong-tolong dalam dosa dan pelanggaran " 14

Jangan sampai ada kata “ dipertimbangkan" pada saat harus memenuhi kebutuhan sesama manusia. Karena dengannya akan tercipta ikatan yang kokoh dan berkembangnya kasih sayang antara orang yang membutuhkan bantuan dan orang yang memberikan bantuan,dan tentunya dalam hal ini bantuan itu berupa pinjaman.

Sedangkan dalam Hadis Rasulullah saw, bersabda yang artinya :

"Hadist Hanad dan Ali bin Hujr menceritakan kepada kami,mereka berkata:Ismail bin Assy menceritakan kepada kami dari Syurahbil bin Muslim AlKhaulani dari Abu Ummah berkata: saya mendengar Rasulullah saw. Bersabda di dalam khutbahnya yaitu pada tahun Haji Wada'; pinjaman itu harus di kembalikan, pinjaman (hutang) wajib mengembalikan hutang, dan hutang itu wajib di bayar".

(HR. Turmudzi) ${ }^{15}$

\section{Rukun dan syarat pinjam meminjam}

Sah tidaknya suatu perbuatan tergantung pada kelengkapan dan kesempurnaan rukun dari perbuatan itu sendiri. Demikian pula dengan pinjam

\footnotetext{
${ }^{14}$ Departemen agama Republik Indonesia, Al-Quran dan terjemahannya (Bandung : Gema Risalah Press,1984),h.156

15 Abu isa Muhammad bin sawrah, sunan Turmudzi, Juz III (Beirut : Dar Kutub alIlmiyah,t.th),h.565
} 
meminjam, sah tidaknya pun tergantung pada kesempurnaan rukunrukunnya. ${ }^{16}$

Adapun rukun pinjam meminjam adalah :

1. Adanya pihak yang meminjamkan disebut Mu'ir.

2. Adanya pihak yang meminjam ( peminjam) di sebut musta'ir.

3. Adanya objek/barang yang di pinjamkan disebut Mu'ar.

4. Ijab dan qabul atau sighat.

Syarat-syarat perjanjian pinjam meminjam antara lain :

1. Bagi pihak yang meminjamkan (mu'ir)

a. Ahli (berhak) berbuat kebaikan sekehendaknya,anak kecil dan orang yang dipaksa tidak sah meminjamkan.

b. Manfaat barang yang dipinjam dimiliki oleh orang yang meminjamkan,walau dengan jalan wakaf atau menyewa sekalipun, karena meminjam hanya bersangkutan dengan manfaat, bukan bersangkutan dengan zat. Oleh karenanya yang meminjam tidak boleh meminjamkan barang yang dipinjaminya,karena manfaat barang yang dipinjam bukan miliknya.

\section{Hak Dan Kewajiban Peminjam}

Peminjam berhak atas barang yang dipinjamkan kepadanya selain tenggang waktu yang diberikan kepadanya, dan tentunya hak itu dimanfaatkan untuk sesuatu yang tidak merusak barang tersebut,karena yang dapat kita miliki hanyalah manfaat dari barang tersebut,karena yang dapat kita miliki hanyalah manfaat dari barang tersebut.

Sedangkan kewajiban peminjam adalah mengembalikan barang pinjaman,setelah ia mendapatkan manfaat yang ia perlukan. ${ }^{17}$

\footnotetext{
16 Hamzah Ya'qub, Kode Etik Dagang Menurut Islam ( Cet I-Bandung : CV.Diponegoro,1984),h.244

${ }^{17}$ Sayyid Sabiq,Fikih Sunnah,Jilid II(Kairo :Dar ai-Fath Lil I'lam al-Farabi,1990),h.319
} 


\section{III.KERANGKA ANALISA SIMPAN PINJAM DALAM PERSPEKTIF HUKUM ISLAM}

\section{A. Mekanisme Simpan Pinjam di Koperasi Mas Sinar Kelurahan Calaca}

Simpan pinjam sebagaimana di tentukan oleh para ulama mesir dikategorikan dalam dua macam yaitu pinjaman konsumtif dan pinjaman produktif. Pinjaman konsumtif adalah debitur mengambilnya untuk memenuhi kebutuhan hidupnya. Menurut syyid Badzarghan pinjamn konsumtif di bagi dalam 3 (tiga) bagian antara lain: (1) pinjaman orang-orang lemah, (2) pinjaman orang-orang yang memerlukan bantuan (amilin), dan (3) Orang yang punya hutang. ${ }^{18}$

Kemudian sayyid Badzarghan menguraikan 3 (tiga) bagian pinjaman konsumtif sebagai berikut :

(1). Pinjaman orang-orang lemah. Mereka tidak memiliki seorang pun yang dapat memenuhi kebutuhan mereka, padahal mereka memilki kebutuhan yang mendesak,misalnya sakit. Kasus ini pada kenyataan menuntut tenggang rasa dan pertolongan masyarakat.

(2). Pinjaman orang-orang yang memerlukan bantuan (amilin). Mereka bukan orang yang miskin sama sekali. Mereka mampu melunasi utangnya pada masa yang akan datang. Artinya secara potensial mereka mampu memenuhi kebutuhan hidupnya,tetapi secara actual ia tidak mampu. Kasus ini adalah kasus pinjaman tanpa bunga.

(3). Orang yang punya hutang. Kondisi mereka lebih baik dari dua kelompok sebelumnya. Contohnya orang yang punya hutang pada orang lain, ia meminjam untuk dapat membayar kembali utangnya dengan cepat tidak memerlukan pinjaman itu untuk memenuhi keperluan hidupnya. ${ }^{19}$

\footnotetext{
${ }^{18}$ Murtadla Mutahhari,Asuransi dan ribar (Cet. I:Bandung : Pustaka Hidayah,1995),h.45

${ }^{19}$ Ibid.,h.46
} 


\section{B. Pendapat Ulama Tentang Simpan Pinjam}

Koperasi Simpan pinjam sebagai wadah untuk menerima tabungan dan memberikan pinjaman kepada anggota dengan syarat yang mudah dan dengan bunga yang rendah, dari definisi yang ada dapat dilihat bahwa fungsi koperasi terhadap anggotanya amatlah bermanfaat dan sangat di butuhkan,tapi simpan pinjam yang terjadi di koperasi Sinar Mas tidak hanya dilakukan antara anggota koperasi,melainkan diberikan kepada orang luar untuk melakukan simpan pinjam. Dari sisi tabungan dan persyaratan peminjaman bukanlah suatu masalah, karena kedua belah pihak sudah menyepakatinya. Tetapi yang menjadi masalah adalah fungsi ekonomi dalam bentuk kegiatan usaha ekonomi yang dilakukan untuk meringankan beban hidup sehari- hari para anggotanya,dengan uang pinjaman relatif rendah yaitu 1-2 \% tidak dipraktekan dalam transaksi pinjam meminjam,malah yang diterapkan adalah bunga sebesar $15 \%$ dari setiap peminjaman.

Member pinjaman adalah suatu perbuatan baik dan sangat di anjurkan, bahkan sebagian ulama salaf sangat menekankan hal ini. Sebagaimana firman Allah swt dalam QS.al-Ma'un(107):7 yang artinya :

"Dan mereka enggan menolong dengan barang berguna". ${ }^{20}$

Ayat ini memberikan keterangan tentang orang-orang yang celaka, yang meliputi orang-orang yang enggan menolong dengan barang-barang yang bermanfaat.

Konsep ta'awun (bertolong-tolongan) dalam kebaikan dalam hal ini berupa pemberian pinjaman kepada orang yang membutuhkan sudah dilakukan oleh koperasi simpan pinjam,tetapi kebaikan itu hanya sebatas pada pemberian pinjaman sementara dalam pengembalian terjadi praktek pendzaliman kepada peminjam yaitu dengan bunga yang tinggi.

Transaksi pinjam meminjam yang ada di koperasi Mas Sinar Kelurahan Calaca mengandung unsure praktek-praktek riba. Karena itu merupakan salah satu perbuatan yang mendzalimi dan melanggar ajaran Alquran. 
Firman Allah swt dalam QS.ar-Ruum(30) :39 yang artinya :

" Dan sesuatu riba' yang kamu lakukan agar menambah harta manusia maka riba' itu tidak menambah pada sisi Allah swt" ${ }^{21}$

Dengan demikian maka ketetapan ayat tersebut tidak hanya terbatas pada haramnya riba' dalam kredit konsumtif, jika kita teliti mengetahui bahwa sebagian besar kredit yang di keluarkan pada waktu itu bersifat produktif dengan mengenakan riba' adalah haram. Karena itu adalah lebih cepat dan sangat patut jika haramnya riba' mencakup kredit konsumtif karena dasar larangan riba' adalah adanya sifat eksploitatif, maka hal ini biasa terjadi pada kredit bersifat konsumtif maupun produktif. ${ }^{22}$

Sedangkan Allamah At-Thabattahaba'I berpendapat bahwa surat ar-Rum ayat 39 dan sesuatu riba' (tambahan) yang kamu berikan agar dia bertambah pada manusia" khusus untuk bunga pinjaman produktif,alasannya adalah :

a) Setidaknya, menggunakan uang tidak sesuai fungsinya itu menyebabkan berubahnya harta sedikit demi sedikit menjadi objek riba'.

b) Riba' menyebabkan bertambahnya modal perdagangan,dan menjadikan potensi lebih besar dari yang sudah ada.

c) Riba' menyebabkan timbulnya kecongkakan dalam masyarakat, sebagian memakan dan menundukan sebagian yang lainnya dan yang tidak kuat akan binasa. $^{23}$

Kesimpulannya modal yang lebih besar akan menghancurkan modal yang lebih kecil. Modal yang kecil tidak mampu menyaingi modal yang besar.

\footnotetext{
${ }^{21} \mathrm{lbid}, \mathrm{h} .97$

${ }^{22}$ Ibid

${ }^{23}$ Murtadla Muthahari,op.cit,h.31-33
} 


\section{Perspektif Hukum Isalam Terhadap Praktek Simpan Pinjam di Koperasi Mas Sinar Kelurahan Calaca.}

Allah memerintahkan hendaklah bertolong-tolong dalam kebaikan dan taqwa serta tidak diizinkan untuk bertolong-tolong dalam kejahatan dan berbuat maksiat,dan tujuannya tidak lain adalah keleluasaan darinya untuk hambahambahnya-Nya, karena semua manusia secara pribadi mempunyai kebutuhan seperti ini tidak terputus selama manusia masih hidup.

Berbeda dengan keuangan negara dan swasta, keungan individu pribadi sedikit sekali menguasai besar kecilnya pendapatannya,ia berkewajiban untuk menyesuaikan. Jadi bila lebih banyak uang yang harus di belanjakan maka lebih banyak uang yang dapat diperoleh dengan meminjamkan dan meminjam. Islam telah mengakui ini sebagai syarat yang diperlukan dalam transaksi manusiawi dengan satu perbedaan

Aturan islam tentang pinjam meminjam adalah selalu mempertahankan keseimbangan antara kecenderungan yang berlawanan, sekalipun sang kreditur telah diarahkan untuk mencegah setiap ketidak adilan yang akan dilakukan terhadap si debitur, sang debiturpun telah diarahkan untuk melakukan setiap usaha yang tulus untuk mengembalikan pinjaman karena kaidah hukum islam menetapkan : "Setiap pinjaman yang memungut tambahan adalah riba". ${ }^{24}$

Sebagaimana firman Allah swt dalam QS.al-baqarah (2):257-276

Artinya : " Orang-orang yang makan (mengambil) riba' tidak dapat berdiri melainkan seperti berdirinya orang yang kemasukan syaitan lantaran(tekanan) penyakit gila. Keadaan mereka yang demikian itu adalah disebabkan mereka berkata (berpendapat), sesungguhnya jual beli itu sama dengan riba', padahal Allah telah menghalkan jual beli dan mengharamkan riba'. Orang-orang yang telah

\footnotetext{
${ }^{24}$ Abu Sura'l Abdul Hadi ,op,cit,.h.131
} 
sampai kepadanya larangan tuhannya,lalu terus berhenti (dari mengambil riba'), maka baginya apa yang telah diambilnya dahulu (sebelum datang larangan) dan urusannya (terserah) kepada Allah. Orang yang mengulangi (mengambil riba),maka orang itu adalah penghuni-penghuninya neraka; mereka kekal di dalamnya. Allah memusnakan riba'dan menyuburkan sedekah. Dan Allah tidak menyukai setiap orang yang tetap dalam kekafiran dan selalu berbuat dosa" ${ }^{25}$

Ayat tersebut menjelaskan bagaimana menbedakan antara perdagangan dengan riba'dan menunjukan bahwa sesungguhnya riba'itu menghancurkan kesejahteraan suatu bangsa. Selanjutnya perintah itu memberikan nasehat kepada orang yang beriman untuk menjauhkan diri dari pungutan bunga atau yang semacamnya yang dapat mengakibatkan kesengsaraan bagi mereka baik itu dunia maupun akhirat. ${ }^{26}$

\section{IV.PENUTUP}

\section{A. Kesimpulan}

Setelah penulis menguraikan bab demi bab mengenai mekanisme simpan pinjam di Koperasi Mas Sinar Kelurahan Calaca Kecamatan Tuminting dan pandangan para ulama tentang praktek simpan pinjam dikoperasi tersebut,maka di akhir bab ini penulis akan memberikan beberapa kesimpulan mengenai seluruh rangkaian isi skripsi tersebut, antara lain :

1. Keberadaan dan tujuan koperasi simpan pinjam sebagai sarana dimana anggota dan masyarakat dapat melakukan aktivitas simpan pinjam, baik untuk memenuhi kebutuhan sehari-hari (Konsumtif) maupun sebagai modal usaha (Produktif)

2. Koperasi Simpan Pinjam Mas Sinar Kelurahan Calaca yang keberadaanya telah memberikan kemudahan bagi masyarakat (peminjam) umtuk melakukan aktivitas simpan pinjam.

\footnotetext{
${ }^{25}$ Departemen Agama,op.cit.,h.75

${ }^{26}$ Alzalur Rahman ,op.cit.h.77-88
} 
3. Mekanisme Simpan pinjam yang di praktekan di koperasi Mas Sinar Kelurahan Calaca secara Hukum Islam (syari'at/fiqih) telah mengalami penyimpangan hukum,hal ini dapat di buktikan dengan penerapan bunga yang melebihi $2 \%$.

\section{B. Implikasi Penelitian}

Dari kesimpulan diatas, maka penulis memberikan saran kepada para pengelola koperasi simpan pinjam secara umum dan koperasi simpan pinjam Mas Sinar secara khusus bahwa ;

1. Keberadaan koperasi Simpan Pinjam Mas Sinar tetap menjalankan tujuannya untuk membantu masyarakat yang lemah secara ekonomi dalam memenuhi kebutuhan mereka.

2. Keberadaan dan tujuan Koperasi simpan pinjam mas sinar disarankan jangan terlalu membebankan para debitur dengan penerapan sistem bunga yang terlalu tinggi, atau melebihi ketentuan-ketentuan yang telah di tetapkan oleh hukum syar'i. 


\section{Daftar Pustaka}

Muhammad Ajaj Al - Khatib , Ushul al-Hadist Mustalahub (Cet, I;- Beirut : Darul Fikr,1989), h.46

H.A. Nawawi Rambe, Fiqh islam (Cet, I;Jakarta : Duta pahala ,1994),h.441 .

Ibid,h.19

M,Solly Lubis , Pembahasan UUD 1945 (Cet,I;Jakarta :CV ,Rajawali ,1987),h.279.

Ibid,h.222 
M.D.J.Al -Barry- sofyan Hadi A.T, Kamus Ulama Kontenporer(Cet .I; Bandung CV.Pustaka setia,2000),h.205

Peter salim dan Yeni salim,Kamus Bahasa Indonesia Kontenporer (Cet.I;Jakarta modern English Press,1991),h.1427.

Ibid,h.1023.

Muhammad Zuhri Dipl Tafl ,at,al,fiqh Empat Mazhab (Cet,I;Semarang : CV .Asy-Syifa',1994),h.448

Suhadrawardi Lubis, Hukum Ekonomi islam (cet.I; Jakarta : Sinar Grafika, 2000), h. 126

\section{Murtdla Muthahari,op.h.67}

Departemen agama Republik Indonesia, Al-Quran dan terjemahannya (Bandung : Gema Risalah Press,1984),h.156

Abu isa Muhammad bin sawrah, sunan Turmudzi, Juz III (Beirut : Dar Kutub al- Ilmiyah,t.th),h.565

Hamzah Ya'qub, Kode Etik Dagang Menurut Islam ( Cet I-Bandung : CV.Diponegoro,1984),h.244 
